\title{
Review of thermal analysis applications in aluminium casting plants
}

\author{
Mile B. Djurdjevic ${ }^{\mathrm{a},}$, Iban Vicario ${ }^{\mathrm{b}}$, Gerhard Huber $^{\mathrm{a}}$ \\ ${ }^{a}$ Nemak Linz, Zeppelinstrasse 24, 4030 Linz, Austria \\ ${ }^{\mathrm{b}}$ Tecnalia Research and Innovation, San Sebastian, Spain \\ ${ }^{\square}$ Corresponding author: Mile.Djurdjevic@nemak.com
}

Received: 15 January 2013; Accepted: 30 August 2013

\begin{abstract}
SUMMARY: Thermal analysis has been applied as a quality control tool in aluminium casting plants for many years. Recently, it has been recognized that the cooling curve and its first derivative analysis offer parameters that can successfully be used in simulation software programs to improve simulation accuracy. The latest developments in cooling curve analysis are related to the application of higher order derivatives, showing that the thermal analysis technique can be applied to calculate the total amounts of different phases precipitated in the solidification process, including copper-rich eutectic. This paper gives a short overview of cooling curve applications in aluminium casting plants, and the impact of lead on solidification characteristic temperatures of AlSi6Cu4 alloy.
\end{abstract}

KEYWORDS: Aluminium solidification characteristic temperatures; Al-Si eutectic modification; Dendrite arm spacing; Dendrite coherency temperature; Grain size; Solid fraction; Thermal analysis

Citation I Cómo citar este artículo: Djurdjevic, M.B., Vicario, I., Huber, G. (2014) "Review of Thermal Analysis Applications in Aluminium Casting Plants". Rev. Metal. 50(1): e004. doi: http://dx.doi.org/10.3989/revmetalm.004

RESUMEN: Revisión de las aplicaciones del análisis térmico en las plantas de fundición de aluminio. El análisis térmico ha sido usado como una herramienta de control de calidad desde hace tiempo en las plantas de fundición de aluminio. Recientemente ha sido reconocido que el análisis de la curva de enfriamiento y su primera derivada ofrecen algunos otros parámetros que pueden ser usados de manera exitosa en los programas de simulación para mejorar su precisión. Los nuevos desarrollos en el análisis de la curva de enfriamiento aplicando las derivadas de orden superior han mostrado que la técnica del análisis térmico puede aplicarse para calcular la cantidad de precipitados en el proceso de solidificación. Este artículo proporciona una pequeña revisión de la aplicación de la curva de enfriamiento en las plantas de fundición de aluminio y del efecto del plomo sobre las temperaturas características de solidificación de la aleación AlSi6Cu4.

PALABRAS CLAVE: Análisis térmico; Características de solidificación del aluminio; Distancia interdendrítica; Fracción sólida; Modificación del eutéctico Al-Si; Tamaño de grano; Temperatura de coherencia dendrítica

Copyright: $₫$ CSIC. This is an open-access article distributed under the terms of the Creative Commons AttributionNon Commercial (by-nc) Spain 3.0 License.

\section{INTRODUCTION}

In the last few decades, modern aluminium casting plants have been forced to produce an increasing number of aluminium cast parts of extremely high quality with less scrap. In order to be able to fulfil these requirements, it was necessary to develop quality tools that will immediately predict the final quality of cast parts prior to casting. Among them, Thermal Analysis (TA) has been widely applied in 
aluminium casting plants to control the quality of the melt. Thermal analysis as a quality control tool has been used for over seventy years in cast iron plants. During the last forty years, there have been few changes in aluminium casting plants in terms of process and quality control. The process and quality control based on the solidification path of aluminium alloys is obtained by plotting temperature versus time. The plotted curve is called the cooling curve and together with its first derivative, it has been used to characterise the solidification path of alloys. Easy to handle, inexpensive, simple, accurate with high repeatability and reproducibility are some of the properties that foster the use of this system at aluminium foundries.

In most aluminium casting plants, thermal analysis equipment has been used to control the master alloy additions and their efficiency. Measuring the depressions produced by primary solidification of $\alpha-\mathrm{Al}\left(\Delta \mathrm{T}=\mathrm{T}^{\alpha-\mathrm{Al}}{ }_{\text {MAX }}-\mathrm{T}^{\alpha-\mathrm{Al}}{ }_{\text {MIN }}\right)$ or the depression produced by AlSi eutectic and its plateau temperature $\left(\Delta \mathrm{T}=\mathrm{T}^{\mathrm{AISi}}\right.$ PLATEAU without Sr $-\mathrm{T}^{\text {AlSi }}$ PLATEAU with $\left.\mathrm{Sr}\right)$, the efficiency of master alloy additions can be evaluated before casting. Besides quality control, cooling curve analysis has recently become an interesting source of input data for simulation software packages. Available simulation software packages have data banks for a few generic Al-alloys. In real production, chemical compositions of Al-alloys have significant variations in comparison with the contents of alloying elements of software package data banks, which significantly affect all solidification parameters (solidification characteristic temperatures, solid fraction, latent heat and many others). Therefore, the application of thermal analysis as input data for simulation packages should be an additional challenge for thermal analysis.

The main aim of this paper is to demonstrate the ability of thermal analysis to control the process, quality and to improve the simulation tools, using the cooling curve and its first and higher order derivatives.

The procedure to plot the cooling curve is very simple. Liquid aluminium melt is preheated to approximately $100{ }^{\circ} \mathrm{C}$ above its liquidus temperature and is then poured into a thermal analysis cup made of ceramic, steel, graphite or sand. One, two or more thermocouples are immersed into the melt, connected to data loggers. Collected signals from thermocouples are transferred into temperatures, providing a plot of temperature versus time. The plot of temperature versus time is identified as the cooling curve, and has been used to describe the solidification path of different alloys. Some thermal weaknesses, which are not visible on the cooling curve, can only be detected using the derivative curve of the cooling curve (Bäckerud et al., 1986a; Sparkman, 2011) started to apply first, second or higher order derivatives of the cooling curve in order to identify more accurately the solidification characteristic temperatures and they recognised some other features of solidified alloys. They also introduced the application of two thermocouples, one located in the centre and the other close to the wall of the thermal analysis cup (Bäckerud et al., 1986a; Bäckerud et al., 1986b). By calculating the difference between the measured temperatures in the centre and in the wall $\left(\Delta \mathrm{T}=\mathrm{T}_{\text {wall }}-\mathrm{T}_{\text {centre }}\right)$ and plotting the difference versus time, he was able to detect the dendrite coherency point/temperature at which dendrites start to impinge on each other during their growth.

Solidification of any Al-alloy starts at liquidus temperature, with the formation of small solid particles of $\alpha-\mathrm{Al}$ nucleus. This temperature delineates the transformation between the liquid and solid condition. Further cooling of the melt, sometimes supported with the addition of some foreign particles (grain refiners), allows the formation of millions of other nucleus and they start to grow with a dendritic form. At a certain temperature below liquidus, these dendrites start to touch each other and form a solid skeleton in the residual melt. The temperature at which this happens is called dendrite coherency temperature and is extremely important for many metallurgical and mechanical properties of cast parts. Cooling the melt to a lower temperature, the primary AlSi eutectic starts to precipitate. In alloys with higher silicon content, this precipitation will take longer and will release significantly more latent heat. The presence of other alloying elements, such as copper, magnesium, iron and particularly strontium and sodium significantly depresses the start of precipitation towards a lower temperature. Close to the end of solidification, copper-rich phases start to precipitate in some alloys with a minimum copper concentration. Depending on the amount of copper and the presence of other alloying elements, the copper phase can appear in several forms (blocky, eutectic and fine eutectic form) (Samuel et al., 1996; Djurdjevic et al., 2001a). The temperature at which the last drop of liquid is transformed into solid is called solidus temperature. In Al- alloys with a minimum concentration of magnesium and iron, their corresponding intermetallics also start to precipitate. The temperature at which these intermetallics appear depends on their concentration and their process parameters. All of the aforementioned characteristic solidification temperatures of Al-alloys can be determined/measured using cooling curve analysis.

\subsection{Theoretical basis}

When a metal is cooled from the liquid to the solid state, exothermic and endothermic events occur. An exothermic reaction during cooling occurs when the atoms become more ordered, increasing the entropy and releasing heat. Metal expands as it is heated. 
In the case of endothermic reactions during cooling, the atoms become less ordered, absorbing heat and shrinking. Plotting the cooling curve and their derivatives versus time, enables these exothermic and endothermic events to be identified, and they can determine different characteristics, such as grain size, eutectic structure, precipitation and formation of different compounds and phases. Metallurgical reactions are presented in the cooling curve as inflection points and as slope changes. Some transformations can only be detected with the first and consecutive derivatives, due to the low heat involved in the transformation. First derivative represents the cooling speed during the specimen solidification.

Temperature is a thermodynamically extensive property that does not depend on the size of the thermal analysis test samples. On the other hand, time is an intensive property that is very sensitive to the thermal mass. Very often the mass of the thermal analysis test sample is a parameter that cannot be constant during thermal analysis experiments. Therefore, from the thermodynamic perspective, use of temperature as the independent variable is more practical.

\section{MATERIALS AND PROCEDURES}

\subsection{Materials}

An AlSi6Cu4 alloy was made by melting a commercial ingot. The chemical composition of the base alloy determined using an Optical Emission Spectroscopy (OES) is presented in Table 1.

\subsection{Thermal Analysis Procedure}

The aluminium alloys were melted in an electric resistance furnace with a capacity of $10 \mathrm{~kg}$. No grain refining or modifying agents were added to the melt. Approximately $250 \mathrm{~g}$ of molten aluminium was poured into thermal analysis steel test cups to obtain the samples. Two especially designed, supersensitive K-type thermocouples (with extra low thermal time constants) were used to record sample temperatures (between $750-400^{\circ} \mathrm{C}$ ). One thermocouple was located in the centre and the second thermocouple was placed near the cup wall. The data acquisition system was a National Instrument NI 9211 data logger with 4 channels; a 24-bit Analogue-to-Digital Converter (ADC, Delta-Sigma type). The applied sampling rate was 10 samples/second with a voltage measurement range of $\pm 80 \mathrm{mV}$. K-type thermocouples have a measurement sensibility $<0.07^{\circ} \mathrm{C}$ (max.

TABle 1. Chemical compositions (wt. \%) of base AlSi6Cu4 alloy

\begin{tabular}{lccccccc}
\hline Si & $\mathbf{C u}$ & $\mathbf{F e}$ & $\mathbf{M g}$ & $\mathbf{M n}$ & $\mathbf{Z n}$ & $\mathbf{N i}$ & $\mathbf{A l}$ \\
\hline 5.78 & 3.96 & 0.07 & 0.13 & 0.01 & 0.01 & 0.009 & rest \\
\hline
\end{tabular}

error for this type of thermocouple for a temperature range between 400 and $800{ }^{\circ} \mathrm{C}$ is $>0.30{ }^{\circ} \mathrm{C}$ ). The tip of the thermocouple was always kept at a constant height of $15 \mathrm{~mm}$ from the bottom of the crucible. The cooling conditions were kept constant during all experiments and were approximately $0.12{ }^{\circ} \mathrm{C} \mathrm{s}^{-1}$. The cooling rate was calculated as the ratio between liquidus and solidus temperature and the total solidification time. Each TA trial was repeated twice. Consequently, a total of eight samples were gathered. The derivatives were calculated using a standard differential quotient derivative algorithm. The derivative for each data point is calculated from the average differential quotients of two data points adjacent to the data point of interest. This procedure is applied to all data points. It is assumed, that data points are available in ascending order in relation to the $\mathrm{x}$-axis of the data object. The derivative is calculated from both sides of a data point as follows:

There are two adjacent data points $\mathrm{P}_{1}\left(\mathrm{x}_{1} ; \mathrm{y}_{1}\right)$ and $\mathrm{P}_{3}\left(\mathrm{x}_{3} ; \mathrm{y}_{3}\right)$ next to the data point $\mathrm{P}_{2}\left(\mathrm{x}_{2} ; \mathrm{y}_{2}\right)$, as we can observe in Figure 1.

The differential quotients must be calculated to obtain the slopes $\mathrm{S}_{21}$ between points $\mathrm{P}_{2}$ and $\mathrm{P}_{1}$ and $\mathrm{S}_{32}$ between the data points $\mathrm{P}_{3}$ and $\mathrm{P}_{2}$ as follows equation (1):

$$
S_{21}=\frac{\partial y_{21}}{\partial x_{21}}=\frac{y_{2}-y_{1}}{x_{2}-x_{1}} \text { and } S_{32}=\frac{\partial y_{32}}{\partial x_{32}}=\frac{y_{3}-y_{2}}{x_{3}-x_{2}}
$$

The derivative $\mathrm{D}_{2}$ of data point $\mathrm{P}_{2}$ is calculated as average of the slopes $S_{21}$ and $S_{32}$ by means of equation (2);

$$
S_{32}=\frac{S_{21}-S_{32}}{2}
$$

The signal-to-noise ratio (SNR) of a signal can be enhanced by hardware or software techniques. The wide use of personal computers in the casting industry and their inherent programming flexibility make software signal smoothing (or filtering) techniques especially attractive. The available literature provides various algorithms for smoothing such as Moving average algorithm, Savitzky-Golay,

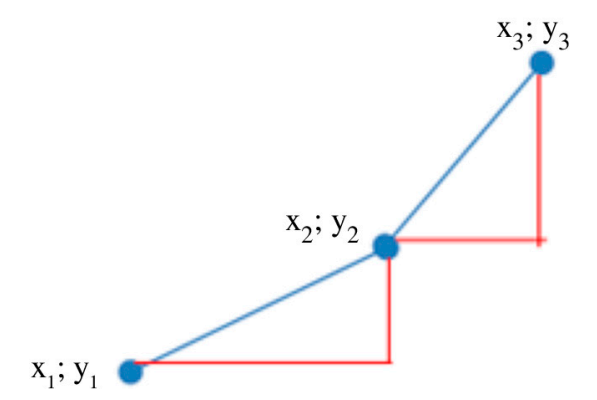

FIgURE 1. Determination of derivatives by the standard differential quotient derivative algorithm. 
Ensemble average and many others. The moving average algorithm has been selected because it is the simplest software technique for smoothing signals consisting of equidistant points. An array of raw (noisy) data $\mathrm{y}_{1}, \mathrm{y}_{2}, \ldots, \mathrm{y}_{\mathrm{n}}$ can be converted to a new array of smoothed data. The "smoothed point" $\left(\mathrm{y}_{\mathrm{k}}\right)$ $\mathrm{s}$ is the average of an odd number of consecutive $2 n+1(n=1,2,3, \ldots)$ points of the raw data $y_{k-n}, y_{k-n+1}$, $\ldots, \mathrm{y}_{\mathrm{k}-1}, \mathrm{y}_{\mathrm{k}}, \mathrm{y}_{\mathrm{k}+1}, \ldots, \mathrm{y}_{\mathrm{k}+\mathrm{n}-1}, \mathrm{y}_{\mathrm{k}+\mathrm{n}}$, i.e.

The odd number $2 n+1$ is usually named filter width. The greater the filter width, the more intense the smoothing effect.

The signal-to-noise ratio may be further enhanced by increasing the filter width or by smoothing the data multiple times. Obviously after each filtering, the first and the last points are lost.

The results of this technique are deceptively impressive because of excessive filtering. Actually, information is lost and/or distorted because too much statistical weight is given to points that are far from the central point. Moving average algorithm is particularly damaging when the filter passes through peaks that are narrow in comparison to the filter width.

Results processing includes the smoothing of the curves by using average windows method with an event number of 21 .

\section{RESULTS AND DISCUSSION}

\subsection{Primary solidification of $\alpha$-Al solid solution}

Depending on the alloy composition, the different solidification temperatures change, but as we are going to observe, the start of solidification and formation of primary $\alpha$-Al solid solution, the precipitation of the Al-Si eutectic along with other eutectics can be obtained. Figure 2, represents the cooling curve of AlSi6Cu4 aluminium alloy and its $\Delta \mathrm{T}$ and first second and third derivative curves.

The blue dotted line represents the cooling curve of investigated alloy. Three distinctive parts can be easily recognized on the cooling curve. The first one is related to the start of solidification and formation of primary $\alpha-\mathrm{Al}$ solid solution. The second plateau is connected to the precipitation of Al-Si eutectic. The third part of the cooling curve shows the precipitation of copper-rich eutectic. The first, second and third derivative curves represented in Figure 2, have been colored green, red and black, respectively. Along with the delta $\mathrm{T}$ curve, the aforementioned curves portray the precipitation areas of the aforementioned phases more clearly and determine their characteristic solidification temperatures more accurately.

Figure 3 represents the segment of Figure 2 related to primary solidification of AlSi6Cu4 alloy. This segment highlights the importance of derivative curves in order to determine the characteristic solidification temperatures more accurately. As can be seen from Figure 3, the intersection of zero axes with the second or third derivatives of the cooling curve have been used to detect the nucleation and minimum temperatures of primary $\alpha-\mathrm{Al}$. The minimum nucleation temperature has been determined using the same aforementioned principle, applying the first derivative curve. Subsequent solidification characteristic temperatures of primary $\alpha-\mathrm{Al}$ segment have been determined applying the aforementioned method: $\mathrm{T}^{\mathrm{LIQ}}{ }_{\mathrm{NUC}}=617.44{ }^{\circ} \mathrm{C}$;

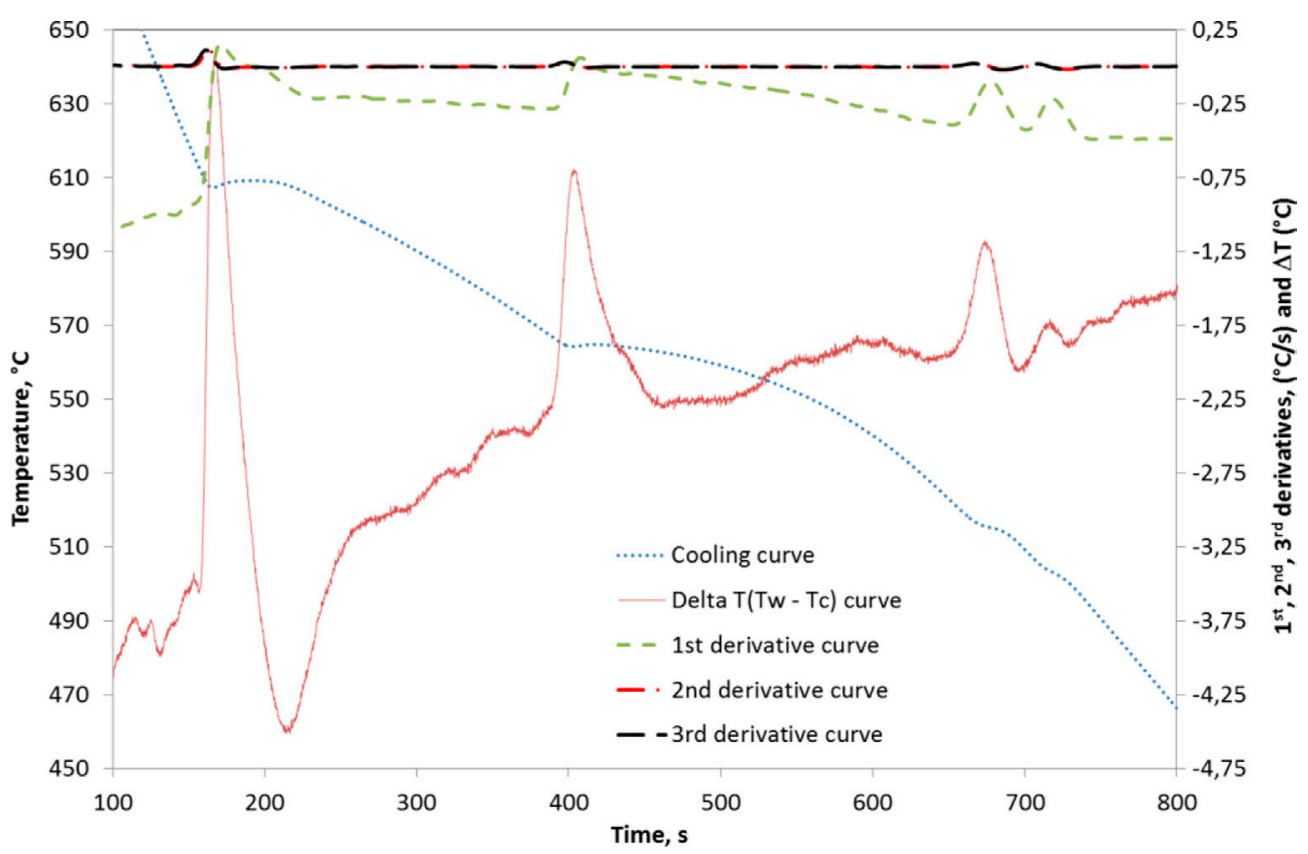

Figure 2. Cooling curve of AlSi6Cu4 alloy and $\Delta \mathrm{T}$, first, second and third derivative curves. 


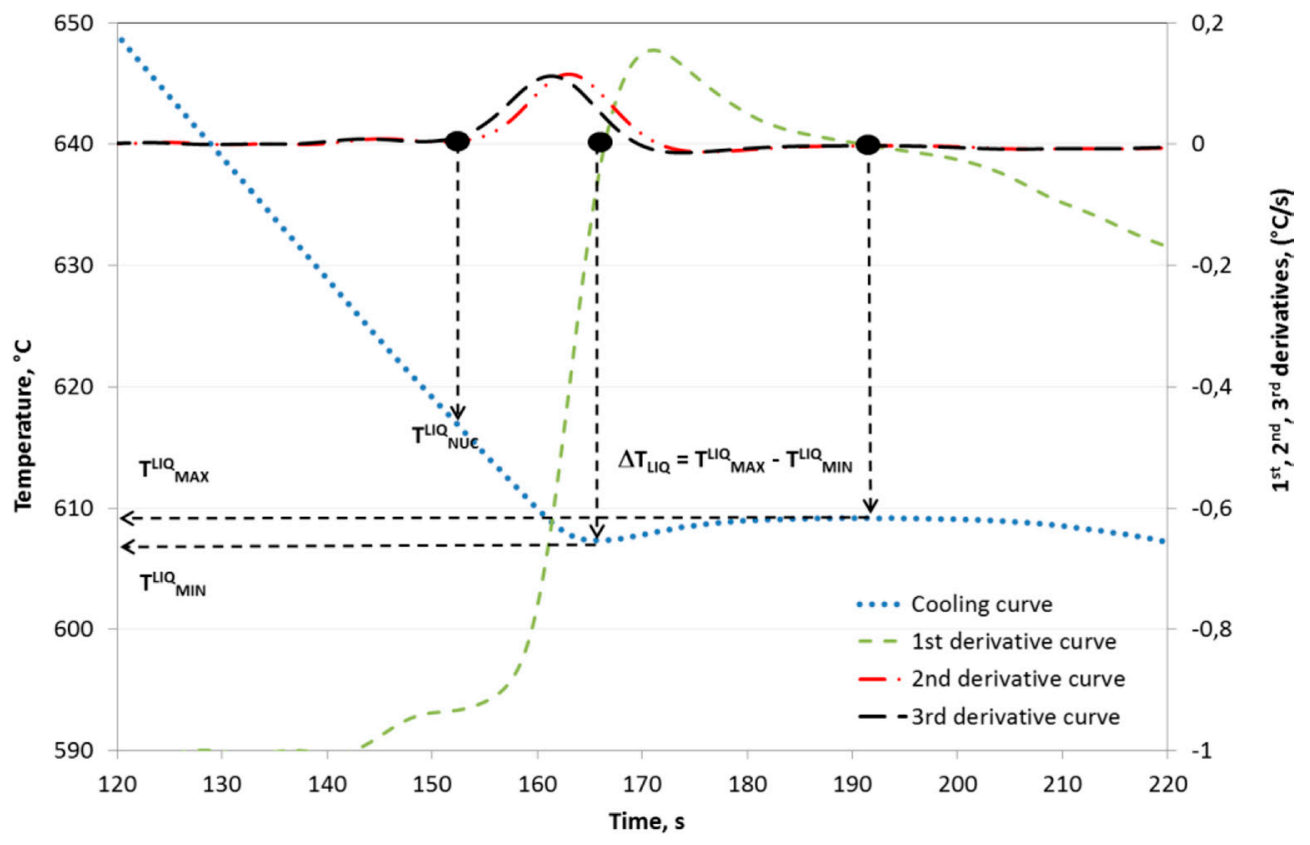

FIGURE 3. Segment of Figure 1 related to primary solidification of $\alpha-\mathrm{Al}$ solid solution.

$\mathrm{T}_{\text {MIN }}^{\mathrm{LIQ}}=607.36{ }^{\circ} \mathrm{C}$ and $\mathrm{T}_{\text {MAX }}^{\mathrm{LIQ}}=609.18{ }^{\circ} \mathrm{C}$. The temperature difference between $\mathrm{T}_{\text {MAX }}^{\mathrm{LIQ}}$ and $\mathrm{T}_{\text {MIN }}^{\mathrm{LIQ}}$ $\left(\Delta \mathrm{T}=\mathrm{T}_{\text {MAX }}^{\mathrm{LIQ}}-\mathrm{T}_{\text {MIN }}^{\mathrm{LIQ}}\right)$ has been used in the foundry as a criterion to estimate the efficiency of grain refiners. The smaller the values of $\Delta \mathrm{T}$, the smaller the grain size and the better the mechanical and metallurgical properties of the cast structure.

\subsection{Dendrite coherency temperature}

Dendrite coherency temperature (DCP) has not often been used in aluminium foundry. But this temperature is a very important parameter for simulation, because it defines the temperature at which mass feeding starts to be restricted. Further feeding is possible by melt flow through interdendritic channels by gravity force (so called interdendritic feeding). This parameter has recently been determined using the cooling curve analysis and applying the two thermocouples technique developed by Bäckerud et al. (1986a) and Bäckerud et al. (1986b).

According to Figure 4, the minimum at the delta T curve corresponds to the dendrite coherency temperature and for this particular alloy it was $608.22^{\circ} \mathrm{C}$.

The different thermal conductivity in the liquid and the solid state is the main reason why at this point there is a difference in the measured temperatures between the two thermocouples, located in the centre and close to wall of thermal analysis cup. The available literature provides a few others methods that have been used to detect this parameter.

Jiang et al. (1999), Djurdjevic et al. (2012a) and Djurdjevic et al. (2001b) used one (Tc) thermocouple located in the centre of the TA cup to determine the DCP temperature characteristics. The DCP is defined as the minimum point on the second derivative curve. At that time, inventors of the single thermocouple technique proved that this is a convenient way of obtaining the required information. However, later work has shown that the thermal signal is sometimes so weak that it cannot be properly detected on the second derivative curve. Colas and a group of authors (Chávez-Zamarripa et al., 2007) applied three thermocouples located in the centre, middle, and close to the wall of steel and graphite crucibles to measure the variation in the thermal diffusivity of A319 alloy (A1Si7Cu3). Comparing this method with the other aforementioned methods, it was concluded that all three methods yield similar results and can be used to evaluate the DCP temperature (Djurdjevic et al., 2012b).

\subsection{Precipitation of Al-Si eutectic}

Aluminium hypoeutectic alloys have been developed to provide a range of properties and characteristics to meet the needs of various applications, mostly automotive. In order to increase alloy properties, the cast silicon structure of these alloys is modified by adding different amount of modifiers (strontium or sodium). Strontium has been widely used in aluminium casting plants as a modifier of hypoeutectic Al-Si cast alloys. Additions of strontium change from a coarse silicon structure to a fine fibrous structure, improving mechanical and metallurgical properties of these alloys. For each Al-Si 


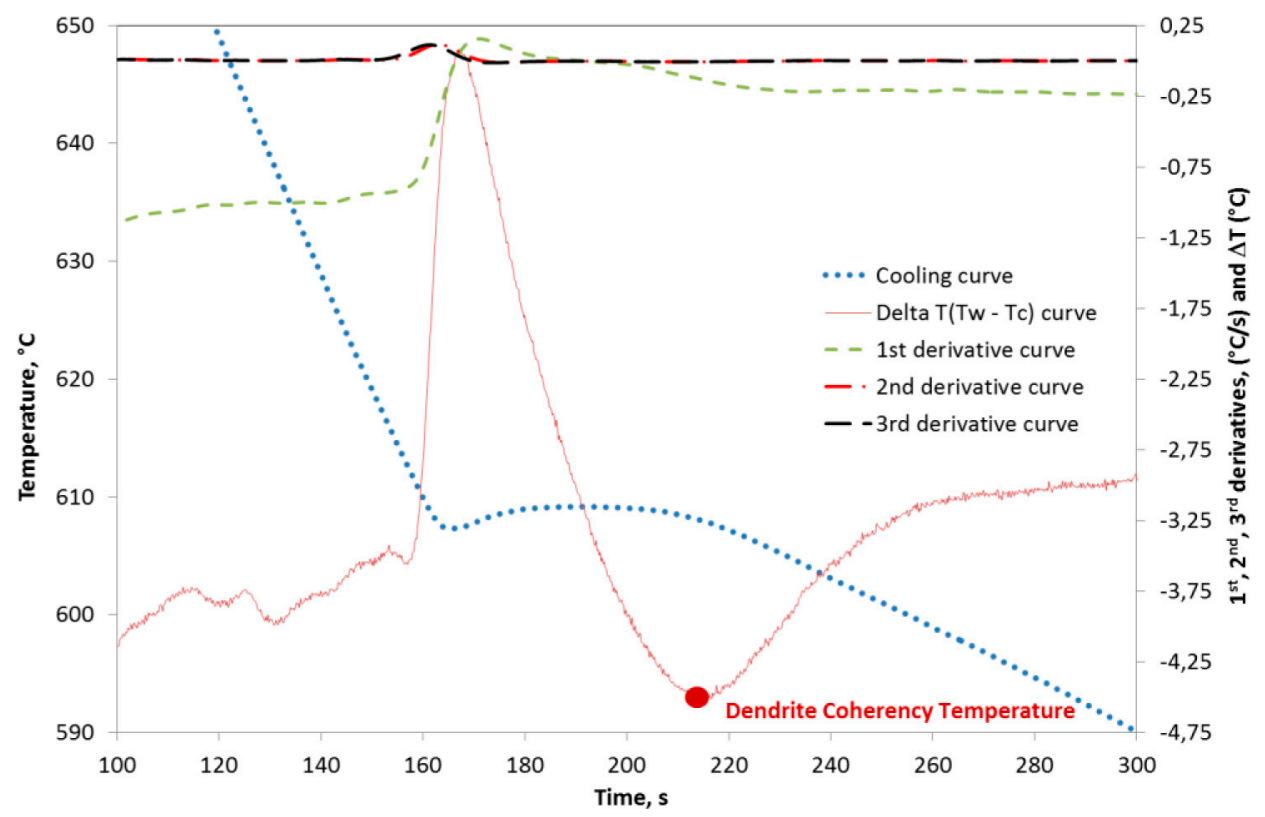

FIGURE 4. Determination of dendrite coherency temperature using the two thermocouples technique.

alloys there is an optimal amount of strontium modifier that can be controlled by using the cooling curve analysis. Addition of strontium depresses the AlSi eutectic temperatures ( $\mathrm{T}^{\mathrm{AISi}}{ }_{\mathrm{NUC}}, \mathrm{T}^{\mathrm{AlSi}}$ and $\mathrm{T}^{\mathrm{ALSI}}{ }_{\text {MAX }}$ ). Operators at foundries are capable of measuring e.g. the $\mathrm{T}^{\mathrm{ALSi}}{ }_{\mathrm{MAX}}$ with and without different strontium contents and calculate the temperature difference $\left(\Delta \mathrm{T}=\mathrm{T}^{\mathrm{AISi}}{ }_{\mathrm{MAX}}\right.$ without $\mathrm{Sr}-\mathrm{T}^{\mathrm{AISi}}{ }_{\mathrm{M}}$ with $\left.{ }_{\mathrm{Sr}}\right)$. The higher the difference, the stronger the silicon particles modification. The advantage of thermal analysis in comparison to classical chemical analysis lies in the fact that the cooling curve is only affected by the active strontium, because only free strontium that is not bonded in some intermetallics can be used to change silicon morphology. In Figure 5 we can observe the region of $\mathrm{Al}-\mathrm{Si}$ precipitation.

Using the derivatives of the cooling curve, all solidification characteristic temperatures related to precipitation of AlSi eutectic can be more accurately

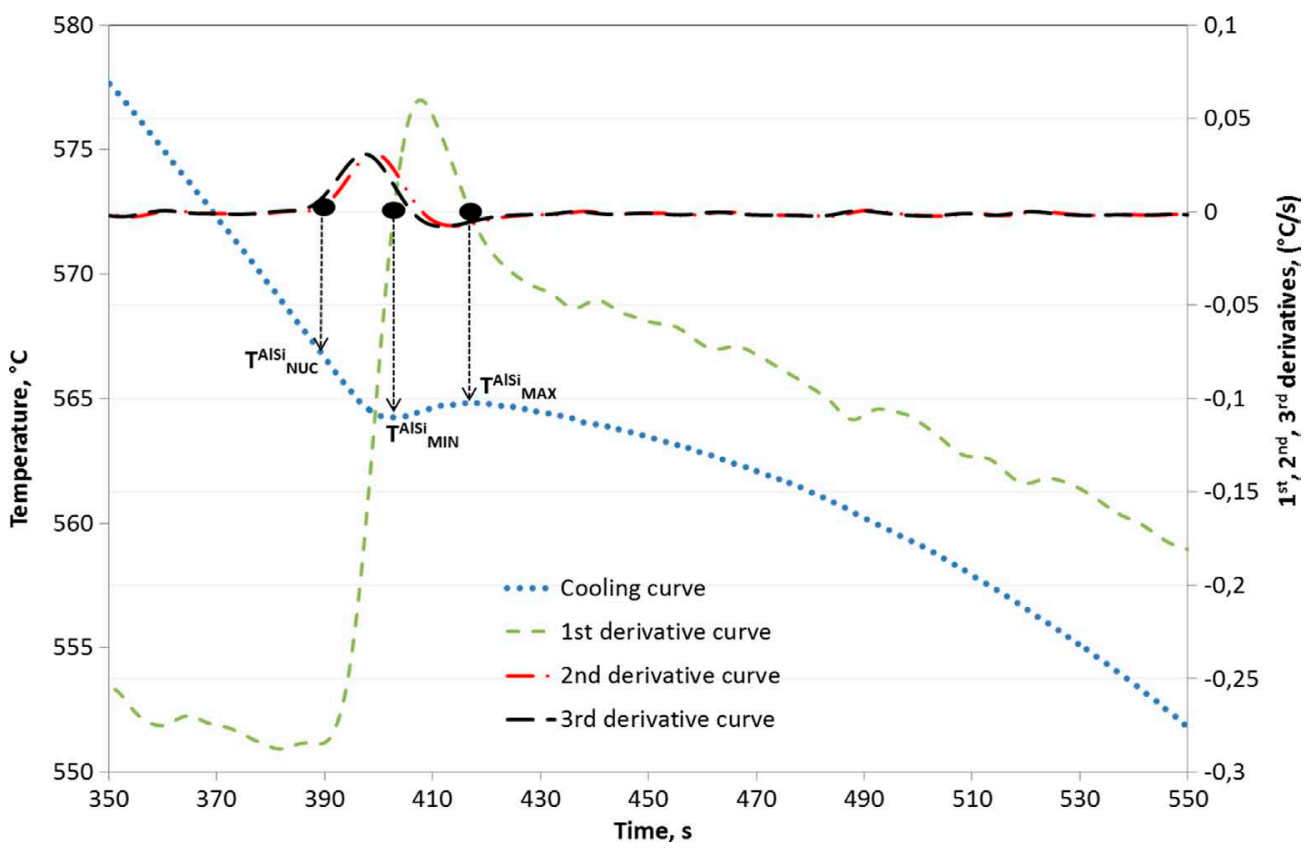

FIGURE 5. Region of Al-Si precipitation. 
determined than reading them directly from the cooling curve. Using second or third derivatives and their intersection with zero value $\mathrm{T}^{\mathrm{AISi}}$ and $\mathrm{T}^{\mathrm{AlSi}}{ }_{\text {MAX }}$ give a value of $567.17{ }^{\circ} \mathrm{C}$ and $564.81{ }^{\circ} \mathrm{C}$, respectively. Using the first derivative and its intersection with the zero axes gives a $\mathrm{T}^{\mathrm{AISi}}{ }_{\text {MIN }}$ value of $564.26^{\circ} \mathrm{C}$.

\subsection{Precipitation of AISiCu-rich phase(s)}

Immediately before the end of solidification, copper-rich phase starts to precipitate on AlSi alloys with a minimum amount of copper. Depending on the amount of copper and some other alloying elements, such as strontium, lead and tin (Jiang et al., 1999 and Djurdjevic et al., 2012c) the start and the end solidification temperatures of this phase can vary, as along with the amount of latent heat released during its solidification. In Figure 6 we can observe the region of copper precipitation.

Using the second or third derivative curves and their intersections with the zero axis $\mathrm{T}^{\mathrm{AlSiCu}}$ and $\mathrm{T}_{\text {soL }}$ have a value of $522.46{ }^{\circ} \mathrm{C}$ and $493.68{ }^{\circ} \mathrm{C}$, respectively. Both temperatures need to be known with a high degree of accuracy in order to be able to propose the best heat treatment conditions for a given alloy. Applying higher temperatures than solidus during solid solution treatment, copper-rich phase can be dissolved around the grain boundaries, diminishing the mechanical properties of heat treated parts. Even though, applying a slightly lower temperature than the minimum temperature for obtaining the optimal mechanical properties, appropriate properties cannot be achieved.

\subsection{Derivative curves plotted versus temperature}

The figures above have shown that during the non-equilibrium solidification of thermal analysis test samples, some thermally weak events cannot be easily detected on the cooling curve. Therefore, the first derivative plotted versus time is used (Backenrud et al., 1986a; Backenrud et al., 1986b; Krohn, 1985).

Recently, several authors (Djurdjevic et al., 2001b; Chávez-Zamarripa et al., 2007; Djurdjevic et al., 2012b; Djurdjevic et al., 2012c; Krohn , 1985 and Canales, 2010) have started to use the first derivative versus temperature plot in order to simplify the detection of the solidification characteristic events during the solidification process, since they can be read directly from the first derivative curves, as shown in Figure 7.

The following three figures (Fig. 8) show the three segments of the first, second and third derivatives related to primary solidification of $\alpha-\mathrm{Al}$, primary Al-Si eutectic and copper-rich eutectic, and how the different temperature values can be determined with a high degree of accuracy.

In Figure 8, the first, second and third derivative curves are plotted against temperature. All solidification characteristic temperatures can be read directly from the corresponding derivative curves with the same accuracy as derivative curves plotted versus time.

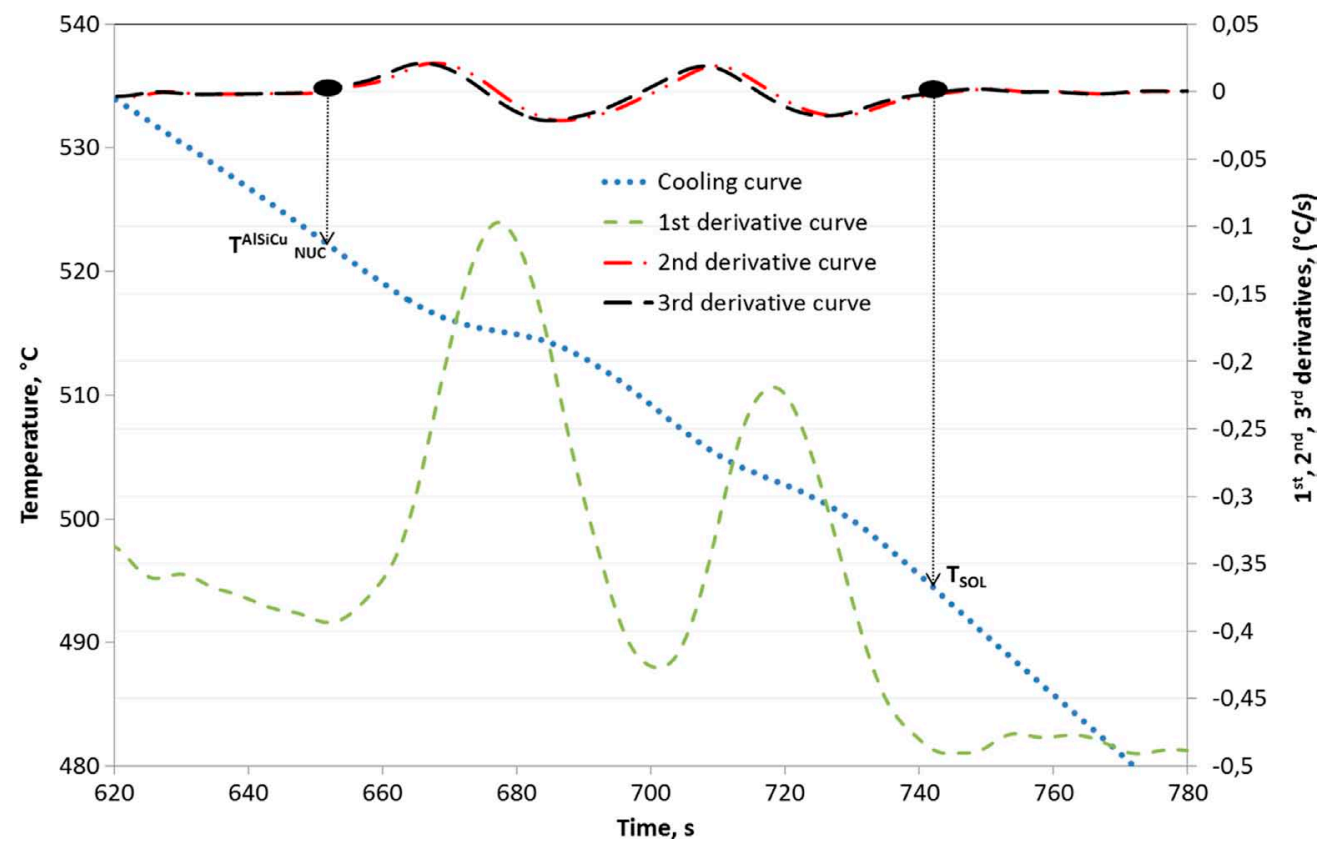

Figure 6. Copper-rich area of precipitation. 


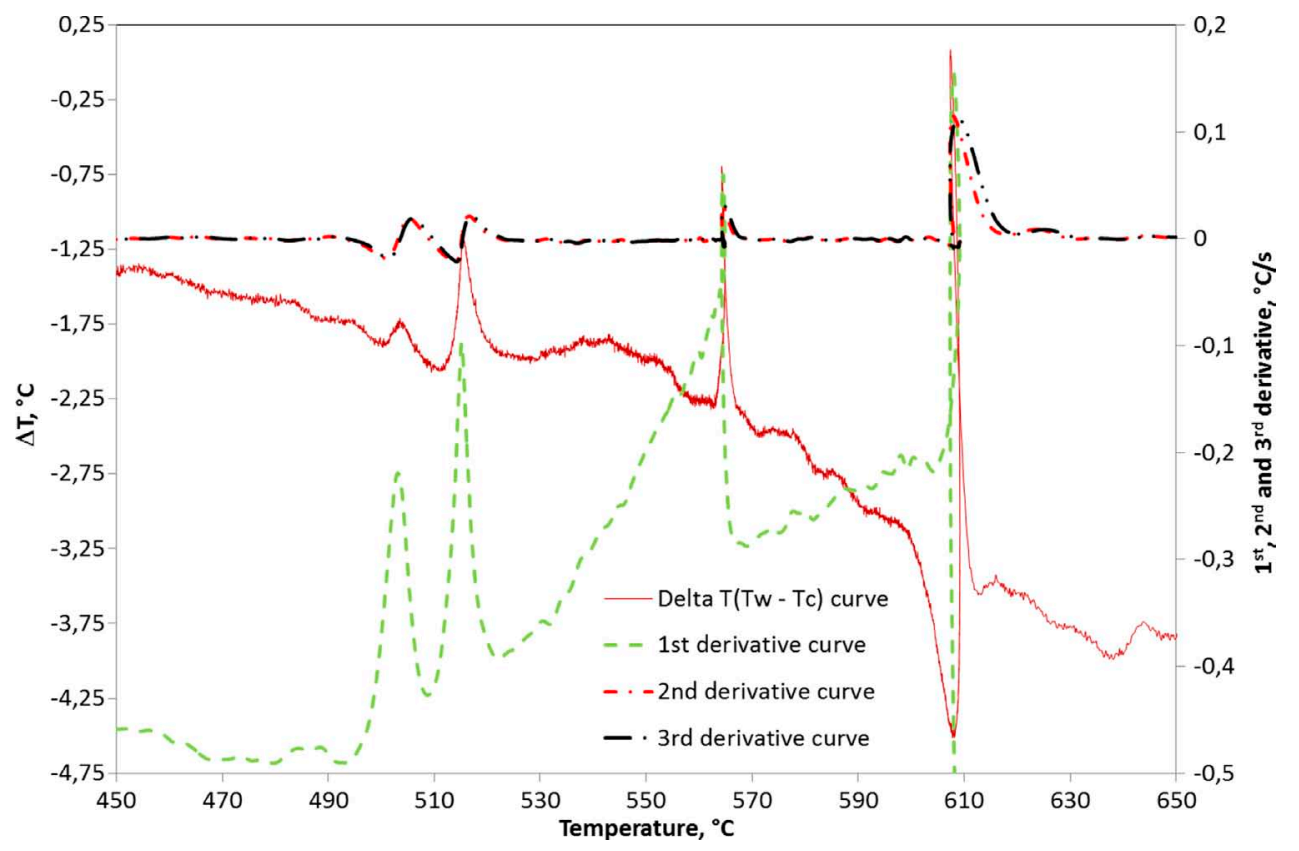

Figure 7. First, second and third derivatives plotted versus temperature.

\subsection{Solid fraction curve}

Solid fraction may be defined as the percentage of solid phase(s) that precipitate between the liquidus and solidus temperatures in a solidifying melt. Accurate information concerning solid fraction is necessary to perform computer simulations of casting feedability and the characterisation of the solidification process, as well as to make predictions concerning casting structure. Available databases used by commercial simulation software packages have only a few selected standard alloys. In the case of more sophisticated alloys with different chemical compositions or the refinement and/or modification treatments, thermal analysis could be a very useful tool to collect the necessary data to improve the simulations and for solid fraction calculation. A cooling curve and its first time derivative can also be used to determine the solid fraction (Upadhya et al., 1989; Kierkus et al., 1999; Fras et al., 1993; Emadi et al., 2002). The shape of the cooling curve is the result of heat lost to the surroundings by the cooling of the test sample, and the heat evolved in the cup during the phase transformation. The amount of heat evolved from a solidifying test sample can be calculated as the integrated area between the first derivative curve (blue line) and the base line (red line) (Fig. 9).

Solid fraction can be calculated numerically by integrating the cumulative area between the first derivative of the cooling curve and the base line (hypothetical cooling curve without phase transformations base line) using either Newtonian or Fourier methods. In this work, the Newtonian method has been applied to calculate the base line. Figure 10 shows the distribution of solid fraction for $\mathrm{AlSi} 6 \mathrm{Cu} 4$ alloys calculated for the temperature range between liquidus and solidus temperature. The advantage of the cooling curve is that the amount of each phase that precipitates during solidification can be calculated using the concept of Newtonian base line. During solidification of AlSi6Cu4 alloys, three distinctive parts can be identified: (i) primary $\alpha$-Al solidification, (ii) precipitation of primary AlSi eutectic and (iii) formation of copper-rich eutectic. Applying the Newtonian approach, the amount of each three micro constituents can be calculated using thermal analysis and its first derivative curve. The calculated percentage of each phase needs to be checked by comparing the measured percentage of the corresponding phases with traditional metallographic techniques. According to previous research (Djurdjevic et al., 2001a) the thermal analysis technique provides a good estimation for the total number of phases that precipitate during the solidification of AlSiCu alloys.

\subsection{Impact of low melting point elements on the solidification path of AISiCu alloys}

Many aluminium casting plants have experienced sudden, unexpectedly high reject rates of cast final products due to a high percentage of porosity and shrinkage defects. In most cases, attention is often directed towards procedure parameters that can influence the solidification process and metal quality. Regarding the process parameters, there are well defined routines in casting plants and any 

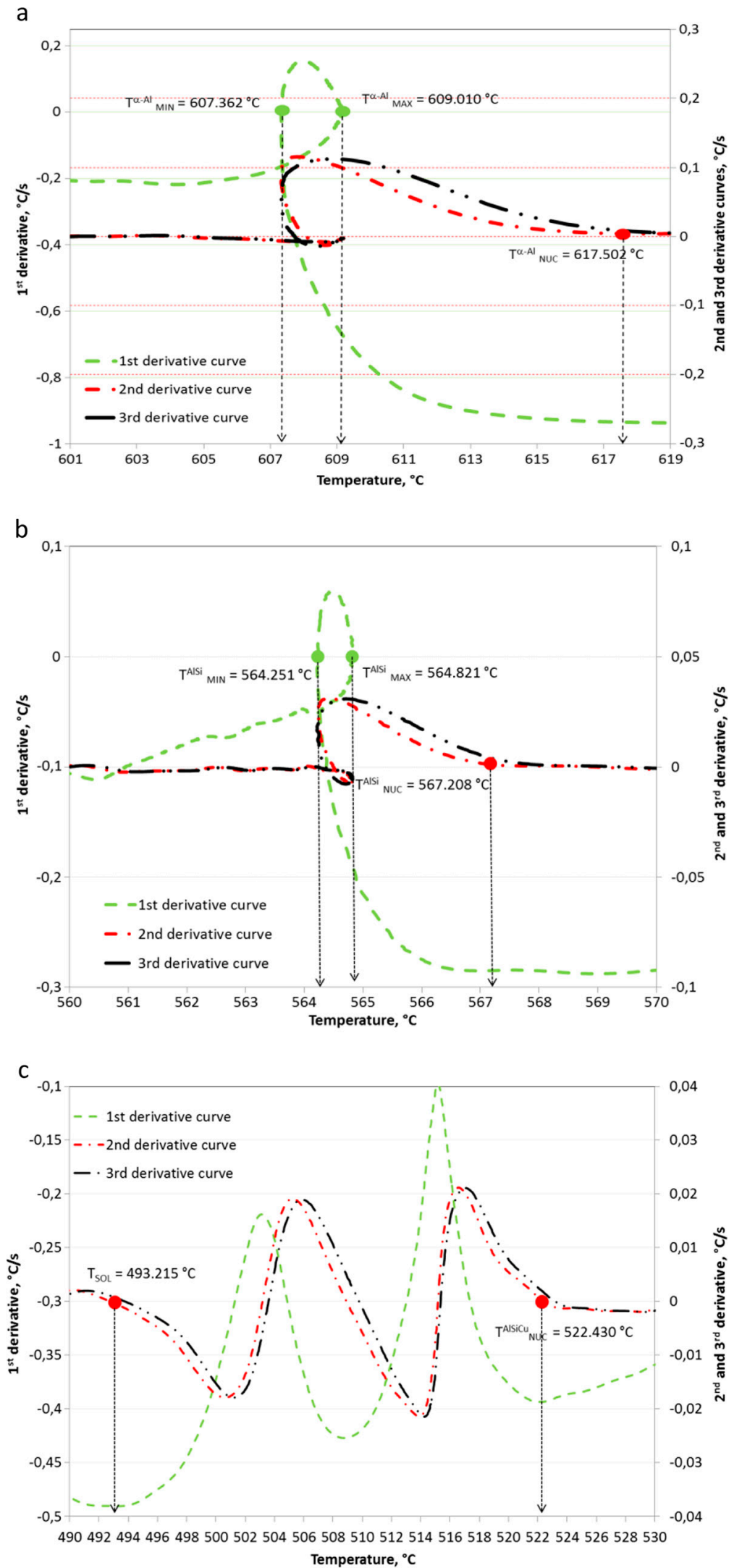

FIGURE 8. Three segments of derivative curves plotted versus temperature: (a) segment related to primary solidification of $\alpha$-Al, (b) segment linked to the precipitation of primary Al-Si eutectic and (c) segment associated to the precipitation of copper-rich eutectic. 


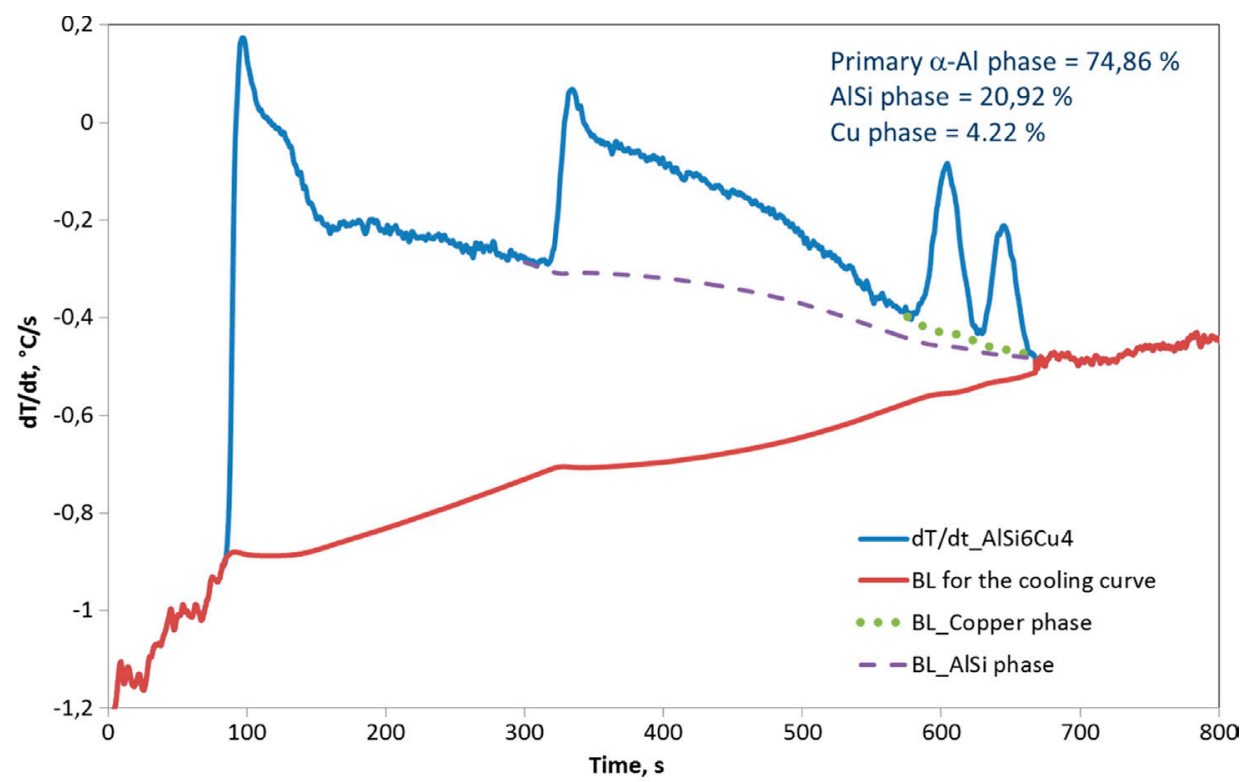

FIgure 9. Cooling curve, its first derivative curve and base lines for AlSi6Cu4 alloy.

variation from the proposed values can easily be identified and corrected, sometimes even automatically. Confusion occurs when an alloy itself starts to be blamed for quality problems. Major and minor alloying elements are very well defined for most commercial alloys. Therefore, it should be no problem to check quickly if some of those elements are out of the defined range. Unfortunately, the main problem arises with trace elements. There is no consensus in literature or in practice regarding the tolerable levels of those elements present in aluminium alloys.

Recently, a few of them (tin and lead) have been recognized as significant and problematic for some aluminium alloys (Djurdjevic et al., 2012c; Emadi et al., 2008; Mohamed et al., 2009). Both elements are not dissolved in pure aluminum, and tin is only partly dissolved in pure copper. During solidification, lead solidifies in the form of pure particles, while tin precipitates either in the form of constituents together with other elements like copper or as pure particles. As Figure 11 shows, lead has a significant effect on the solidus temperature of the $\mathrm{AlSiCu}$ alloy.

It is obvious that the higher content of lead increases the solidification interval of $\mathrm{AlSiCu}$ alloys making them more prone to shrinkage porosity.

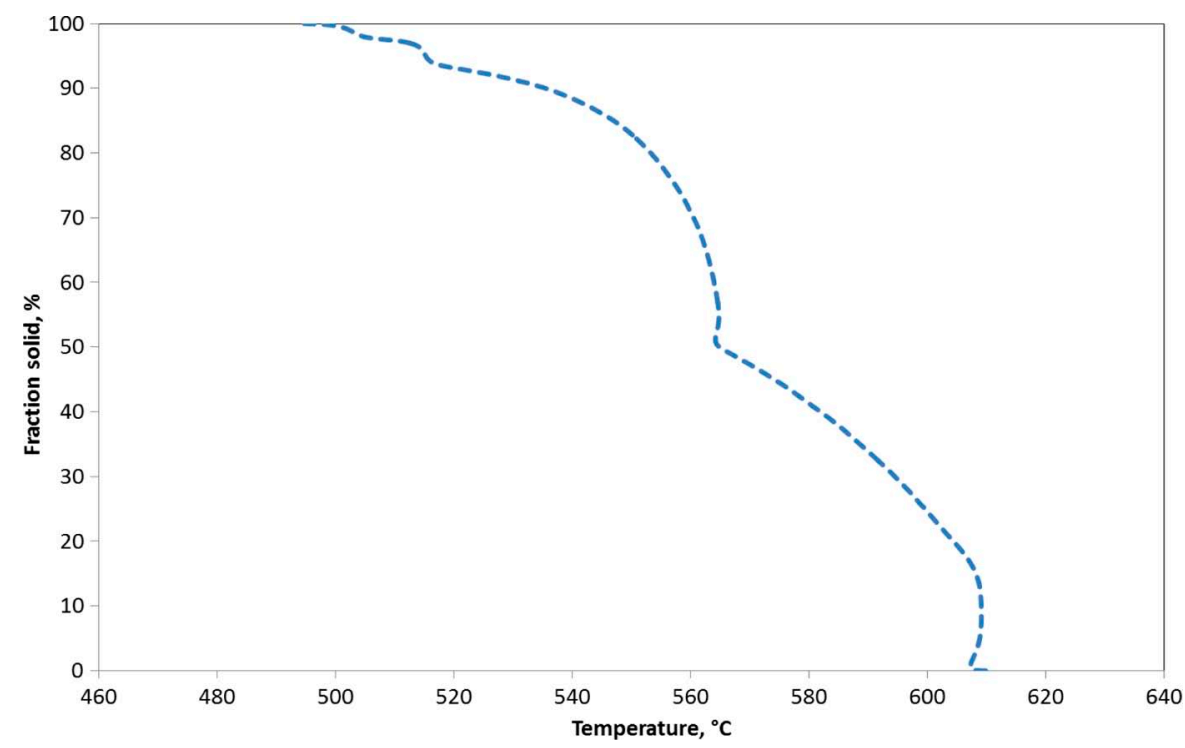

FIGURE 10. Solid fraction curve for AlSi6Cu4 alloy. 


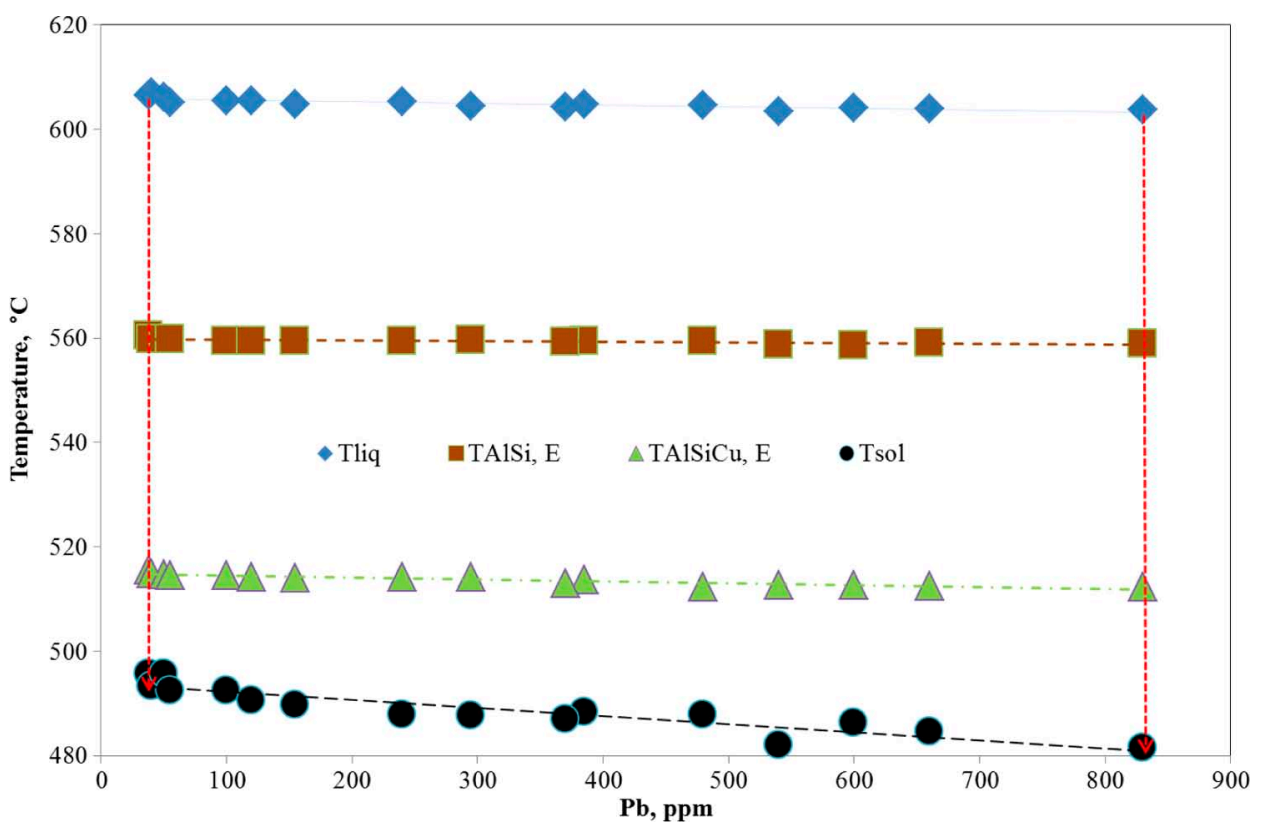

FIGURE 11. Impact of lead on characteristic solidification temperatures of AlSi6Cu4 alloy.

Similar behavior has been identified with the higher content of tin present in $\mathrm{AlSiCu}$ alloys (Djurdjevic et al., 2012c). The cooling curve analysis can be used to predict such behavior and suggests that the operator should take some actions to eliminate defects in the cast structure.

The cooling curve method is useful for commercial applications for many reasons: it is simple, inexpensive and provides consistent results. This technique is a good choice for drawing fundamental relationships between cooling curve characteristics and alloys. A state-of-the-art thermal analysis system should be able to quantify parameters such as: grain size, dendrite coherency point, level of silicon modification, low melting point of secondary eutectic(s), solid fraction and other solidification characteristic temperatures. The interest in applied simulation in the aluminium casting industry has extended significantly in recent decades. There are three main reasons for this: (i) the need to increase the productivity and quality of cast products (ii) to speed up design process and (iii) to investigate the influence of different process parameters without the need for expensive experimental trials. The accuracy of casting simulation depends greatly on the quality of the available physical and thermophysical material properties provided by the software database. Databases currently used by commercial simulation software packages for casting industry usually come with material properties for only a few selected standard alloys. In the case of more sophisticated alloys with differing chemical compositions or with refinement and/or modification treatments, thermal analysis can be a very useful tool in order to collect the missing parameters or more accurate thermophysical data for investigated alloys. This paper has demonstrated that the cooling curve is capable of improving simulation software packages with such data. Therefore, cooling curve analysis should be used more often to update existing data banks and provide new ones that will allow the solidification path of investigated intrinsic cast parts to be predicted more accurately. The main advantage of cooling curve analysis is the ability to provide high quality information on the foundry floor in a very short period of time. Several researchers are even looking to extend the benefits of cooling curve analysis. One of them is Sparkman (2011) who has proposed the next logical steps in the use of thermal analysis: introducing the application of higher order derivatives in order to measure the energy signatures of different microstructures. Higher order derivatives (up to fifth) offer the possibility of opening up thermal analysis to become much more than just a quick chemistry/inoculant check. With this information, according to Sparkman, thermal analysis should allow the amounts of different phases and defects (i.e. shrinkage porosity) that appear in the cast structure of $\mathrm{Al}$-alloys to be calculated.

\section{CONCLUSIONS}

At present, aluminium casting industries are using significant amount of primary and secondary aluminium alloys. Quantifying as many parameters as possible from the cooling curve would allow process engineers to enhance the control of the casting process. Thermal analysis is used to evaluate 
the following processing and materials parameters: grain size, dendrite coherency temperature, dendrite arm spacing, level of $\mathrm{Al}-\mathrm{Si}$ eutectic modification, solid fraction as well as the characteristic temperatures of various metallurgical reactions between liquidus and solidus temperatures. Use of modern data acquisition systems and computer processing thermal analysis becomes a powerful tool for casting process control. However, the data collected using cooling curve analysis should be applied in existing simulation software in order to improve the accuracy of simulation.

\section{REFERENCES}

Backenrud, L., Chai, G. Tamminen, J. 1986a. Solidification Characteristics of Aluminium Alloys. Volume 2: Foundry Alloys, AFS/Skanaluminium, Oslo, Norway.

Backenrud, L., Krol, E., Tamminem J. 1986b. Solidification Characteristics of Aluminium Alloys. Volume 1 and 3, AFS/ Skanaluminium, Oslo, Norway.

Canales, A.A., Talamantes-Silva, J, Gloria, D., Valtierra, S., Colas, R. 2010. Thermal analysis during solidification of cast Al-Si alloys. Thermochim. Acta 510 (1-2), 82-87. http://dx.doi.org/10.1016/j.tca.2010.06.026.

Chávez-Zamarripa, R., Ramos-Salas, J.A., TalamantesSilva, J., Valtierra S., Colás, R. 2007. Determination of the Dendrite Coherency Point during Solidification by Means of Thermal Diffusivity Analysis. Metall. Mater. Trans. A, 38 (8), 1875-1879. http://dx.doi.org/10.1007/ s11661-007-9212-8.

Djurdjevic, M.B., Kasprzak, W., Kierkus, C.A., Kierkus, W.T. Sokolowski, J.H. 2001a. Quantification of cu enriched phases in synthetic 3xx aluminum alloys using the thermal analysis technique. AFS Transactions No 01-089, 1-12.

Djurdjevic, M., Kierkus, W.T., Sokolowski, J.H. 2001b. 40th Annual Conference of Metallurgists of CIM, Edited by M. Sahoo and T. J. Lewis, MetSoc, ISBN: 1-894475-12-7, Toronto, Canada, pp. 443-451.
Djurdjevic, M.B., Odanovic, Z., Zak, H. 2012a. Detection of Dendrite Coherency Temperature of Aluminum Alloys Using Single Thermocouple Technique. Praktische Metallographie 49 (2), 86-98. http://dx.doi.org/10.3139/147.110147.

Djurdjevic, M. B., Sokolowski J., Odanovic, Z. 2012b. Determination of dendrite coherency point characteristics using first derivative curve versus temperature. J. Therm. Anal. Calorim. 109 (2), 875-882. http://dx.doi.org/10.1007/ s10973-012-2490-4

Djurdjevic, M.B., Muche, D., Stauder, B., Eigenfeld, K. 2012c. Effect of Sn on the Characteristic Solidification Temperatures of AlSi6Cu4 Alloy, Praktische Metallographie, 49 (06), 356-376. http://dx.doi.org/10.3139/147.110102.

Emadi, D., Whiting, L. 2002. Determination of solidification characteristics of Al-Si alloys by thermal analysis. AFS Transactions 110 (Paper No 02-033), 285-296.

Emadi, D., Whiting, L., Schmid-Fetzer, R. 2008. ICCA 11, Aachen, Germany, pp. 328-335.

Fras, E., Kapturkiewicz, W., Burbielko, A., Lopez, H.F. 1993. A new concept in thermal analysis of castings. AFS Transactions 101, 505-511.

Jiang, H., Kierkus, W.T., Sokolowski, J.H. 1999. Determining Dendrite Coherency Point Characteristics of Al Alloys using Single-Thermocouple Technique. AFS Transactions $68,169-172$.

Kierkus, W.T. Sokolowski, J.H. 1999. Recent Advances in Cooling Curve Analysis: A New Method of Determining the 'Base Line' Equation. AFS Transactions 66, 161-167.

Krohn, B. R. 1985. Thermal Analysis: Metallurgical Thumbprinting. Modern Casting, March, 1-7.

Mohamed, A.M., Samuel, F.H., Samuel, A.M., Doty, F.W. 2009. Effects of Individual and Combined Additions of $\mathrm{Pb}, \mathrm{Bi}$, and Sn on the Microstructure and Mechanical Properties of Al-10.8Si-2.25Cu-0.3Mg Alloy. Metall. Mater. Trans. A, 40 (1), 240-254. http://dx.doi.org/10.1007/s11661-008-9692-1.

Samuel, F.H., Samuel, A.M., Doty, H.W. 1996. Factors controlling the type and morphology of cu-containing phases in 319 al alloy. AFS Transactions 104, 893-901.

Sparkman, D.A. 2011. Microstructure by Thermal Analysis. AFS Transactions 119, (Paper 11-068), 1-8.

Upadhya, K.G., Stefanescu, D.M., Lieu, K., Yeager, D.P. 1989. Cornputer-Aided Cooling Curve Analysis: Principles and Applications in Metal Casting. AFS Transactions 47, 61-66. 